\title{
EFFICIENCY OF HYBRID POWER STATIONS AND FACTORS AFFECT THE EFFICIENCY
}

\author{
AHMED KH A. E. ALKHEZIM \\ The Public Authority for Applied Education and Training, High Institute of Energy-Kuwait
}

\begin{abstract}
In this paper the performance and efficiency of hybrid power stations are studied, taking into account the factors affect on hybrid types stations. This will include using good tracking solar system, good photovoltaic cooling system for solar cells and vibrations of the wind structure. Efficiency of solar systems affected by temperature increases, the efficiency of such systems can be increased by using some type of cooling for photovoltaic cells and panels. Power generated from wind turbines are effected by vibrations of wind turbines towers and structures, decreasing the values of such structures may increase the output power of wind turbines stations by a considerable values. An equation to calculate the overall efficiency of hybrid power plan is generated. The overall efficiency of combined or hybrid power plant is calculated and it reaches to 70\%. It is found that there are many factors affects the final energy produced from hybrid energy systems (solar and wind). Two main factors are studied here: high temperatures, and vibrations both have a bad effect on the performance of the energy systems. As the temperature and vibrations increased the efficiency of the energies system (single or combined) is decreased. Hybrid power plants reduces costs, spaces and improves the overall efficiency of the renewable energy systems.
\end{abstract}

KEYWORDS: Wind Energy, Solar Energy, Mixed (Hybrid) Energy Source, Performance

Received: May 11, 2020; Accepted: Jun 01, 2020; Published: Jul 09, 2020; Paper Id.: IJMPERDJUN2020250

\section{INTRODUCTION}

Many techniques can be utilized to expand the proficiency of the universes and crossover power plant stations extraordinarily those relying upon sun based radiation. The photovoltaic (PV) module's capacity yield can be expanded by expanding the occurrence sun based radiation falling on a PV module as indicated by the inborn attributes of the PV cells. Then again, introducing a following framework not just builds the underlying expense of the sun powered PV framework as various mechanized segments are required, yet in addition it lessens the life of the mechanical plan of a sunlight based PV framework outline since it will require a portable and movable structure. Studies have indicated that the proficiency of an indistinct silicon cell diminishes by $0.05 \%$ with each $1^{\circ} \mathrm{C}$ temperature increment and on account of a crystalline silicon sunlight based cell, the abatement ranges from $0.4 \%$ to $0.5 \%$ [1]. A cooling framework can upgrade the presentation of heavenly bodies. At present, the test for a sunlight based PV framework is to plan a savvy cooling framework. Various arrangements have been proposed to diminish the working temperature of a PV panels. S. Dubey determined the reliance between the transformation proficiency and temperature of PV cells [1]. A half and half photovoltaic/warm close planetary system is a dependable strategy for cooling the PV boards [2]. In this framework, the PV boards are connected to the cooling framework. Water or air, which is utilized as cooling operators, is flowed around the PV board to cool the sun powered cells. The key factor of this framework is that the warm water originating from around the sun oriented board can be utilized for local use. What's more, a past report [3] proposed a cooling model, in which water and air were both seen as cooling 
specialists. The presentation of water as a cooling operator is higher than air utilized as a cooling specialist. The elite of water is because of the expansion in the coating zone of water. So also, air and uninvolved cooling for improving the temperature of photovoltaic boards was surveyed [4, 5].

The electrical efficiency of the cells diminishes with temperature increment. Cooling can improve the electrical creation of standard level board PV modules, since cooling shields the PV cells from arriving at temperature at which irreversible harm happens. It has been discovered that the effectiveness and yield intensity of PV module is conversely corresponding to its temperature [6]. So for solar system, and to improve the exhibition of sun based cells in the board's module is required, a system has been built up that streamlines the board's activity by guaranteeing that it works at the purpose of most extreme force for as long a period as could be expected under the circumstances. This method is called most extreme force point track(MPPT). Figure 1 shows this conduct of photovoltaic cells. Fiorentini et al. (2015) depicted a trial examination concerning the exhibition of a Hybrid Model Predictive Control (HMPC) framework executed to control a novel sunlight based helped HVAC framework adjusting the Team UOW Solar Decathlon house, the general champ of the Solar Decathlon China 2013 rivalry. This HVAC framework comprises of an air-based photovoltaic warm (PVT) authority and a stage change material (PCM) warm store incorporated with a regular ducted invert cycle heat siphon framework. The framework was intended for activity during both winter and summer, utilizing daytime sun powered radiation and night sky radiative cooling to build the vitality effectiveness of the cooling framework. The outcomes from this primer test work have exhibited the estimation of the HMPC approach in ideally controlling the sun oriented helped HVAC framework in the Solar Decathlon house. Results show that the HMPC controller effectively chose the proper working mode to accomplish various goals, including: upkeep of indoor solace conditions inside a characterized, and conceivably factor, warm solace band; and streamlining of the general vitality proficiency of the framework utilizing all accessible on location vitality assets [7]. Zerhouni et al. (2010) a fast methodology for top force following is proposed. The framework PV generator - load is advanced, when the working point in direct coupling is very close to the MPP of the PV generator, with the goal that the worldwide effectiveness of the framework is adequate. Another technique is proposed. It depends on reconfiguring on-line the SCA by changing the associations between various modules so as to limit the misfortunes because of burden and activity conditions. Two systems for upgrades are picked for testing in this investigation, whatever the heaps and working conditions [8].

Adhikar and Bhattacharya(2011) a simplified approach is sketched out with the expectation of complimentary vibration investigation of these long, thin structures considering the dirt structure connection. The explanatory strategy depends on an Euler-Bernoulli bar segment with versatile end bolsters. The versatile end-underpins are considered to show the adaptable idea of the association of these frameworks with soil. A shut structure estimated articulation has been inferred for the principal regular recurrence of the framework. This new articulation is an element of geometric and versatile properties of wind turbine tower and properties of the establishment including soil. The proposed straightforward articulation has been freely approved utilizing a careful numerical technique, research facility based exploratory estimation and field estimation of a genuine wind turbine structure. The outcomes acquired in the paper shows that the proposed articulation can be utilized for a brisk appraisal of the crucial recurrence of a wind turbine considering the dirt structure connection [9]. Rahman et al. (2015) gives the uses of uninvolved, dynamic and semi-Active and vibration control techniques for structures, particularly for wind turbines. In addition, this paper Reviews on damping gadgets required for vibration relief of structures. These damping gadgets have been executed broadly in wind turbines for expanding their proficiency by moderating vibration. This paper likewise audits and surveys the exhibition of various control arrangements to control the framework info and 
force contribution of damping gadgets [10]. Karmouche and Bentamy (2016) broke down the plan of one of the most significant segment of a wind turbine which is the pinnacle. The structure and investigation of the pinnacle will be centered on little wind turbines. It will break down the impacts of stacking on the pinnacle, the ideal pinnacle tallness and the check of wellbeing against twisting and clasping. In a further investigation, this work is to give an advancement technique to limiting the pinnacle mass and assessing the additional estimation of this enhancement regarding cost [11]. Vidyanandan (2017) talked about the yield power produced by a photovoltaic module and its life expectancy relies upon numerous perspectives. A portion of these elements include: the kind of PV material, sunlight based radiation power got, cell temperature, parasitic protections, cloud and other concealing impacts, inverter productivity, dust, module direction, climate conditions, land area, link thickness and so on. This paper surveys not many of the central point that fundamentally influence the presentation of sunlight based PV frameworks [12]. Mustafa et al. (2020) scrutinized the dependability and legitimacy of existing examinations that emphasis on the effect of different natural factors on a photovoltaic (PV) framework's exhibition. Just because, four ecological variables (the gathering of residue, water beads, feathered creatures' droppings, and halfway concealing conditions) influencing framework execution are explored, at the same time, in one examination. The outcomes got from this examination show that the aggregation of residue, concealing, and winged animal fouling significantly affects PV current and voltage, and thus, the gathered PV vitality [13].

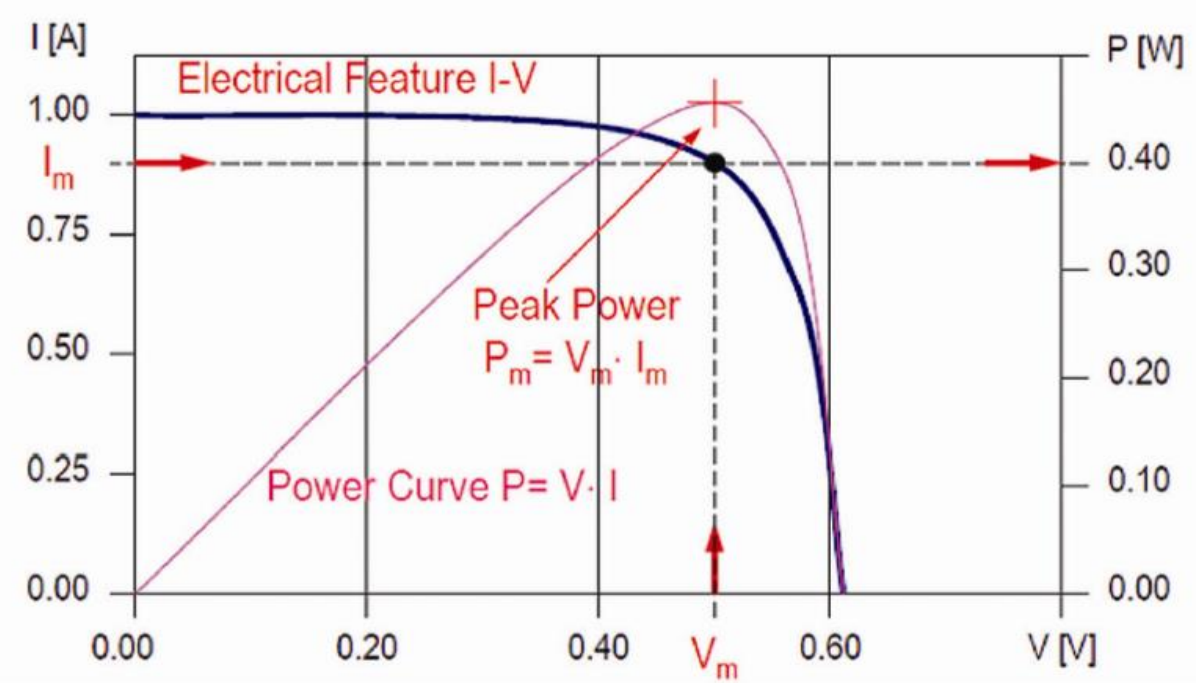

Figure 1: Electric Feature (I-V) and Power Curve for a Single Photovoltaic Cell [6]

The maximum power output (MPP) can be obtained MPP current $\left(\mathrm{I}_{\mathrm{mp}}\right)$ and voltage $\left(\mathrm{V}_{\mathrm{mp}}\right)$ using relation:

$$
P_{m p}=I_{m p} V_{m p}
$$

In estimating the PV module performance, the temperature dependence of the maximum powerpoint efficiency is an important parameter and is given by the following:

$$
\eta_{m p}=\frac{I_{m p} V_{m p}}{G_{T} A_{m p}}
$$

Where $\mathrm{G}_{\mathrm{T}}$ :is the solar Irradiance $\left(\mathrm{W} / \mathrm{m}^{2}\right), \mathrm{A}_{\mathrm{m}}$ :is the area of module $\left(\mathrm{m}^{2}\right)[5]$.

We have two types of solar systems: linear concentrator system as shown in figure 2. It is usually Long U shaped 
mirrors focus sunlight onto fluid-filled tubes that run along each mirror. Once the fluid is heated, it flows to a heat exchanger where it is used to boil water into steam. The steam runs a turbine generator, producing electricity [14].

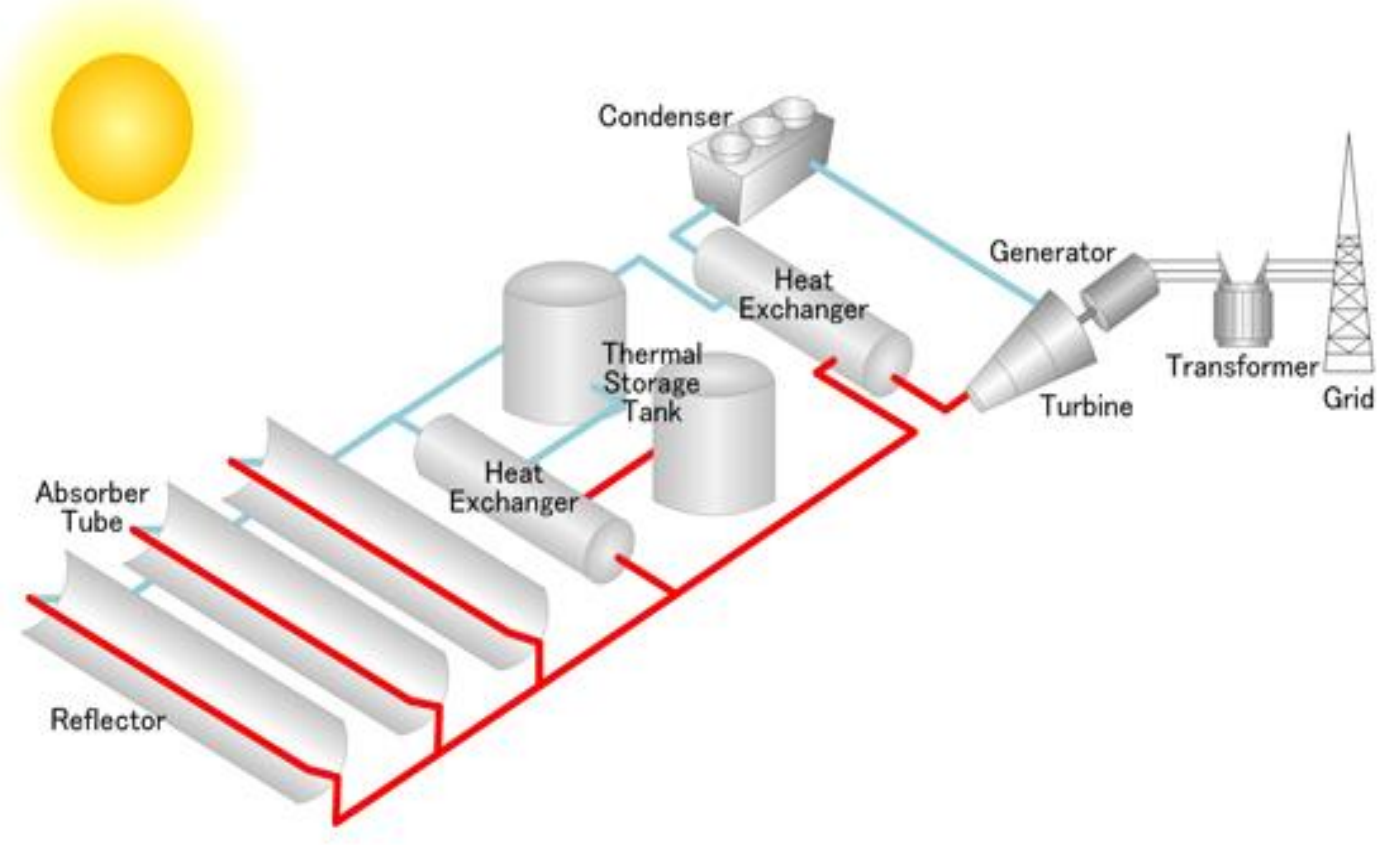

Figure 2: Linear Concentrator System (Sources: National Renewable Energy Laboratory. 2013, August 20).

And Dish/Engine System -Figure 3. Dish-shaped mirrors concentrate lighton to a power conversion unit. Inside this unit, a fluid-filled thermal receiver is heated to power a small electricity generating turbine [14].

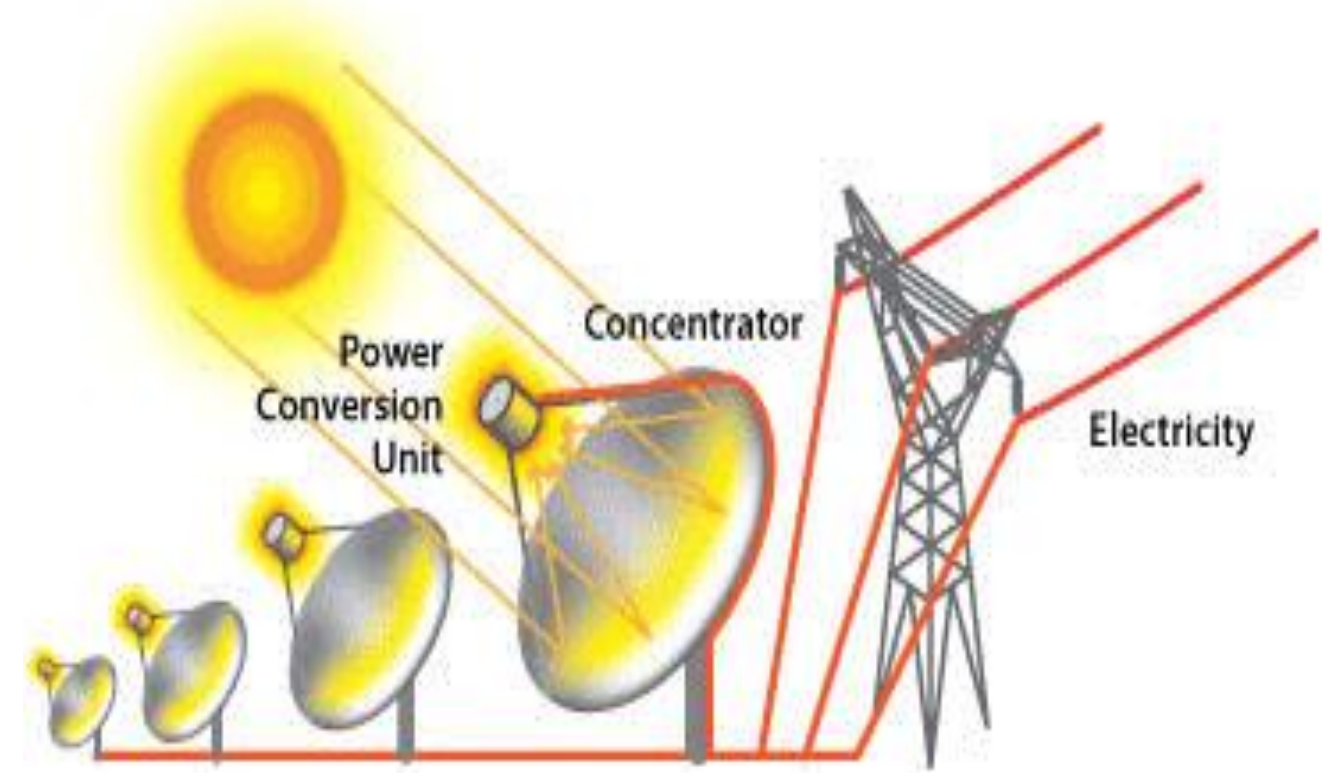

Figure 3: Dish/Engine System (Sources: US Department of Energy, 2013, August 20).

Table 1 below shows the effect of temperature on energy released from solar system, it can be noticed that as the temperature increases, the power decreases. So using some kind of cooling in such systems will increase the power output and so efficiency. 
Table 1: Voltages and currents and power of solar panels without cooling

\begin{tabular}{|l|l|l|l|l|l|}
\hline Si. No. & Time & $\begin{array}{l}\text { Temperature } \\
\left({ }^{\circ} \mathrm{C}\right)\end{array}$ & $\begin{array}{l}\text { Voltage } \\
(\mathbf{V})\end{array}$ & $\begin{array}{l}\text { Current } \\
(\mathbf{A})\end{array}$ & $\begin{array}{l}\text { Power } \\
(\mathbf{W})\end{array}$ \\
\hline 1 & $11: 00 \mathrm{am}$ & 32 & 17.5 & 1.51 & 25.9 \\
\hline 2 & $11: 15 \mathrm{am}$ & 50.2 & 17.2 & 1.47 & 25.38 \\
\hline 3 & $11: 30 \mathrm{am}$ & 52.4 & 17.26 & 1.44 & 24.38 \\
\hline 4 & $11: 45 \mathrm{am}$ & 60 & 17.2 & 1.44 & 24.61 \\
\hline 5 & $12: 00 \mathrm{pm}$ & 62.3 & 16.92 & 1.43 & 24.36 \\
\hline 6 & $12: 15 \mathrm{pm}$ & 63 & 16.87 & 1.43 & 24.12 \\
\hline 7 & $12: 30 \mathrm{pm}$ & 64.1 & 16.7 & 1.43 & 23.88 \\
\hline 8 & $12: 45 \mathrm{pm}$ & 65.63 & 16.72 & 1.42 & 23.745 \\
\hline 9 & $1: 00 \mathrm{pm}$ & 64.78 & 16.62 & 1.42 & 23.61 \\
\hline 10 & $1: 15 \mathrm{pm}$ & 64.79 & 16.23 & 1.45 & 23.54 \\
\hline 11 & $1: 30 \mathrm{pm}$ & 64.7 & 16.41 & 1.43 & 23.47 \\
\hline 12 & $1: 45 \mathrm{pm}$ & 64 & 16.45 & 1.43 & 23.53 \\
\hline 13 & $2: 00 \mathrm{pm}$ & 63.5 & 16.39 & 1.42 & 23.53 \\
\hline
\end{tabular}

It can be noticed that power which equals (voltage*current) decreases with increasing in temperature. But if some appropriate cooling system is used the output power may increase or be stable. Table 2 shows the power generated by solar panels without and with cooling comparison. It is clear that the power in the case of cooling is greater [15].

\section{Wind Section of Hybrid Power Plant}

In harnessing energy from a wind turbine, the wind spins the blades of a turbine that then spins a shaft that is connected to a generator. This process converts the kinetic energy of the wind into mechanical energy. Figure 4 shows what happened at wind turbine blades.

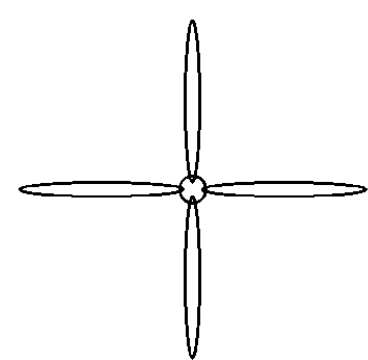

Front View

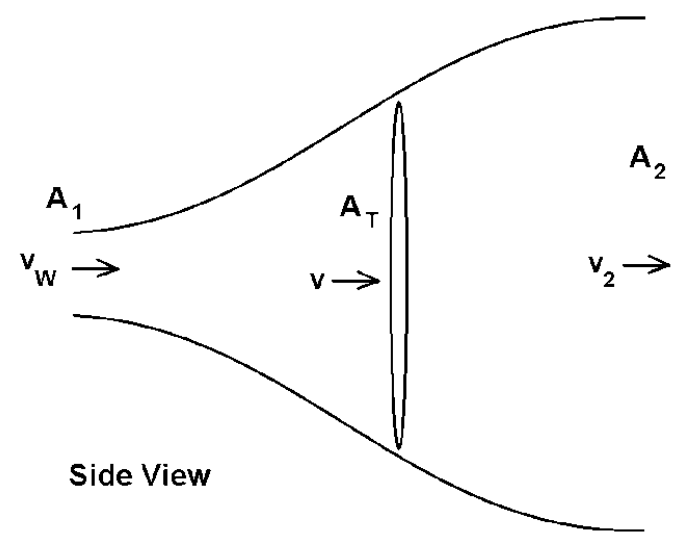

Figure 4: Wind turbines blades and wind interaction

By utilizing material science and analytics ideas, it is conceivable to infer equations that speak to the speed that augments the turbine power and the greatest conceivable change productivity of a wind turbine. These play a significant in boosting the measure of vitality we can separate from the wind. Since we have articulations for the force separated at the turbine $\left(P_{T}\right)$ and the all-out force accessible from the wind $\left(P_{\text {total }}\right)$, we would now be able to make an articulation for the productivity of the of the perfect wind turbine[16].The efficiency of the wind turbine system is given as: 


$$
\eta=\frac{P_{T}}{P_{\text {total }}}
$$

Where:

$$
P_{T}=\frac{1}{4} \rho A_{T} v_{w}^{3}\left(1-\left(\frac{v_{2}}{v_{w}}\right)^{2}+\left(\frac{v_{2}}{v_{w}}\right)-\left(\frac{v_{2}}{v_{w}}\right)^{3}\right)
$$

And,

$$
P_{\text {total }}=\frac{1}{2} v_{w}{ }^{2} \frac{d m}{d t}=\frac{1}{2} v_{w}{ }^{2} \dot{m}=\frac{1}{2} \rho A_{T} v_{w}{ }^{3}
$$

Where $\rho$ is the density of air $\left(\mathrm{kg} / \mathrm{m}^{3}\right), A_{1}$ is the is the cross-sectional area of the wind approaching the turbine, $A_{2}$ is the cross-sectional area of the air stream after the turbine, $A_{T}$ is the area of the turbine, $v_{w}$ is the upstream wind speed, $v$ is the air velocity at the turbine blades, and $v_{2}$ is the velocity of the downstream air after it has passed the turbine. The crosssectional areas are in units of $\mathrm{m}^{2}$, and the airspeed (velocity) in $\mathrm{m} / \mathrm{s}$. so the efficiency of the wind turbine is

$$
\eta=\frac{1}{2}\left(1-a^{2}+a-a^{3}\right)
$$

Where $a=v_{2} / v_{w}$ is the velocity ratio [16].

Dimensions of the blade edge is essential to the point that, based on the measurements the air impacts of wind changes. The measurement ought to be precise during the drawing and computations. So the different parameters that ought to be dealt with during drawing the wind cutting edge are primarily the state of the airfoil, length of edge, measurement of the root, length of each segment, harmony length and so forth all these shift with the adjustment in wind speed [17]

\section{RESULTS AND DISCUSSIONS}

The efficiency of hybrid power plant is effected by many parameters like dimensions of the blades of the wind turbine, power coefficient, vibrations of the wind tower, materials of the photovoltaic cells, existing of a good cooling system for cells. The total efficiency of the hybrid power plant is the superposition of two systems (solar and wind systems in parallel) and so the total efficiency of the hybrid power plant can be written as (by analogy with reliability[18]):

$$
\eta_{\text {total }}=1-\left(1-\eta_{\text {solar }}\right)\left(1-\eta_{\text {wind }}\right)
$$

So,

$$
\eta_{\text {total }}=1-\left(1-0.5\left(1-a^{2}+a-a^{3}\right)\right)\left(1-\frac{I_{m p} V_{m p}}{G_{T} A_{m}}\right)
$$




\section{Data Collection}

For the very first experiment, the area $(\mathrm{LxW})$ of aluminum foil was kept equivalent to that of the sun oriented board $(0.54 \mathrm{~m}$ $\mathrm{x} 0.36 \mathrm{~m}$ ). Approaching beam and reflector surface. A silver covered plane reflection of $0.1944 \mathrm{~m}^{2}$ region was utilized. Three distinctive size aluminum foil reflectors were utilized to acquire a standardized an incentive for the impact of the reflectors on sun based board yield. The size of the primary, second, and third reflector was $0.0648 \mathrm{~m}^{2}$ (33\% of board size), $0.1296 \mathrm{~m}^{2}$, and $0.1944 \mathrm{~m}^{2}$, individually [5].

A moderate climate period from March to May, the greatest sun oriented irradiance was $0.70 \mathrm{kWh} / \mathrm{m}^{2}$, which is still not exactly the pinnacle sun powered irradiance characterized for the sun oriented board. In summer (June-July-Aug and Sept), this worth expanded to $0.95 \mathrm{kWh} / \mathrm{m}^{2}$ however the issue is the temperature that likewise increments for sun based board and henceforth again sun based PV framework can't create power to its full limit [5]. From [5] $\mathrm{V}_{\mathrm{mp}}$ is taken as 17.5V and $\mathrm{I}_{\mathrm{mp}}$ is taken as1.15 A. For wind energy side, some portion of the half breed power station a (speed proportion $\left.\left(v_{2} / v_{w}\right)\right)$ is taken in the scope of 0.25:0.01:0.34[16].

Figure 5 shows the impact of changing speed proportion (an) on the productivity of the half and half force plant as the speed proportion is changed while the sun based proficiency is fixed at 0.85 , while figure 6 shows the impact of changing of the gatherer (aluminum foil) in the range (0.0648 to $0.1944 \mathrm{~m}^{2}$ relying upon [5] on the effectiveness of the mixture power plant if the wind framework productivity is 0.65 .

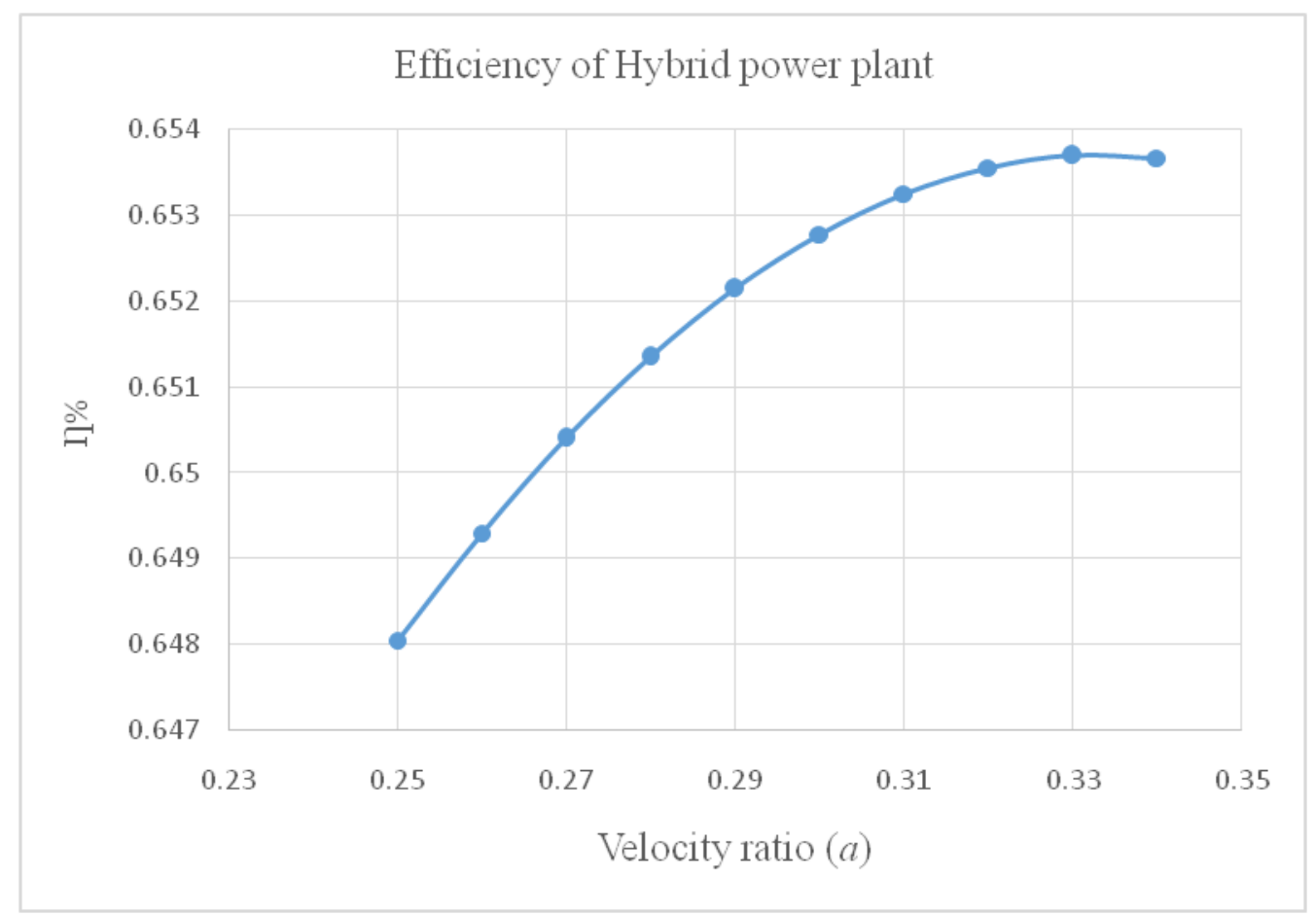

Figure 5: Efficiency of the Wind Section of the Hybrid Power Plant vs. Velocity Ratio (at Solar Sector Efficiency of $85 \%$ ) 


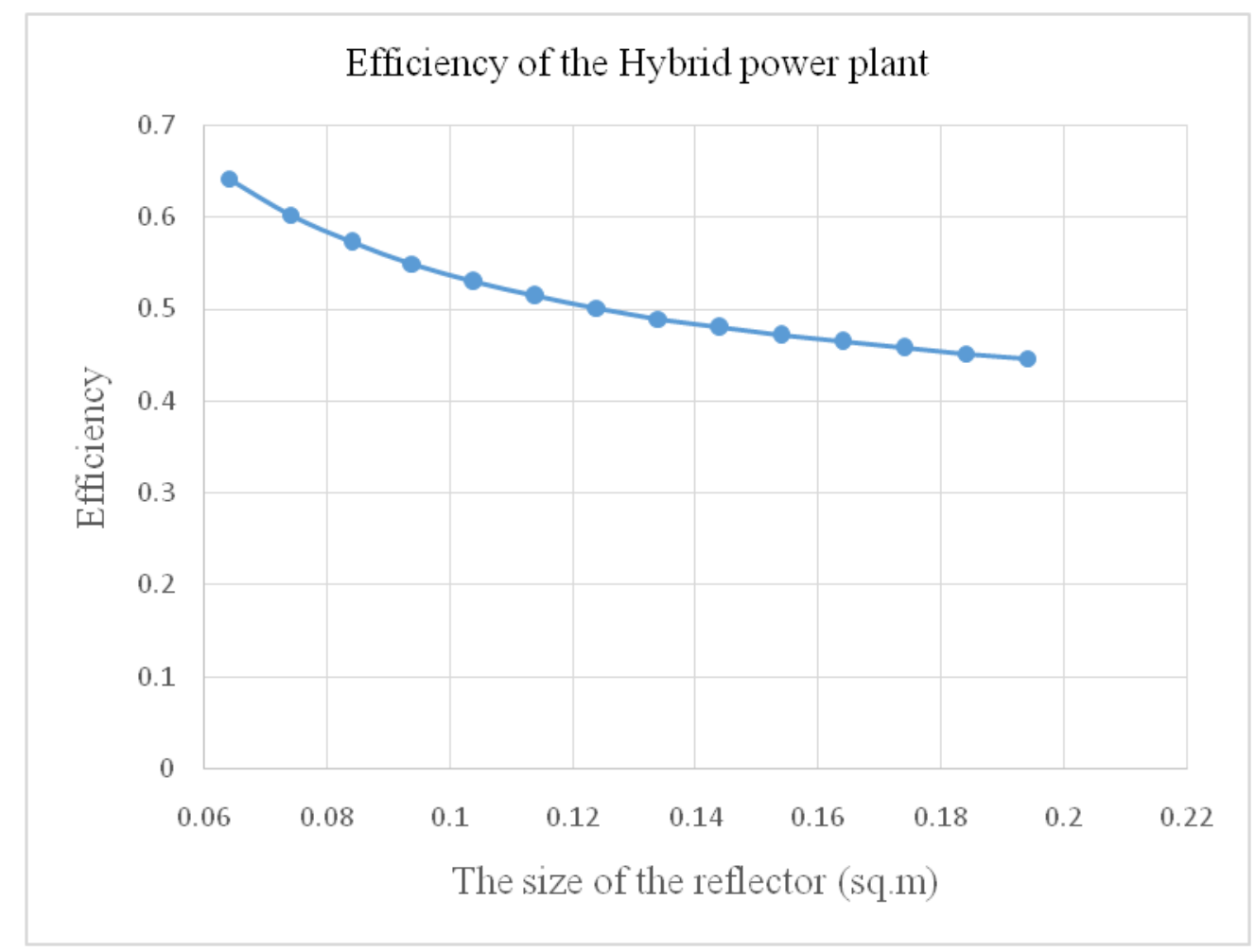

Figure 6: Efficiency of the Solar Section of the Hybrid Power Plant and its Relation with Reflector Size (wind at $65 \%)$

\section{Factors Affects Solar and Wind Energies Systems}

There are two main factors affects the performance and final efficiencies of the solar and wind energy system that are: vibrations and high temperatures.

Figure 7: Power generated by solar panels without and with cooling [15].

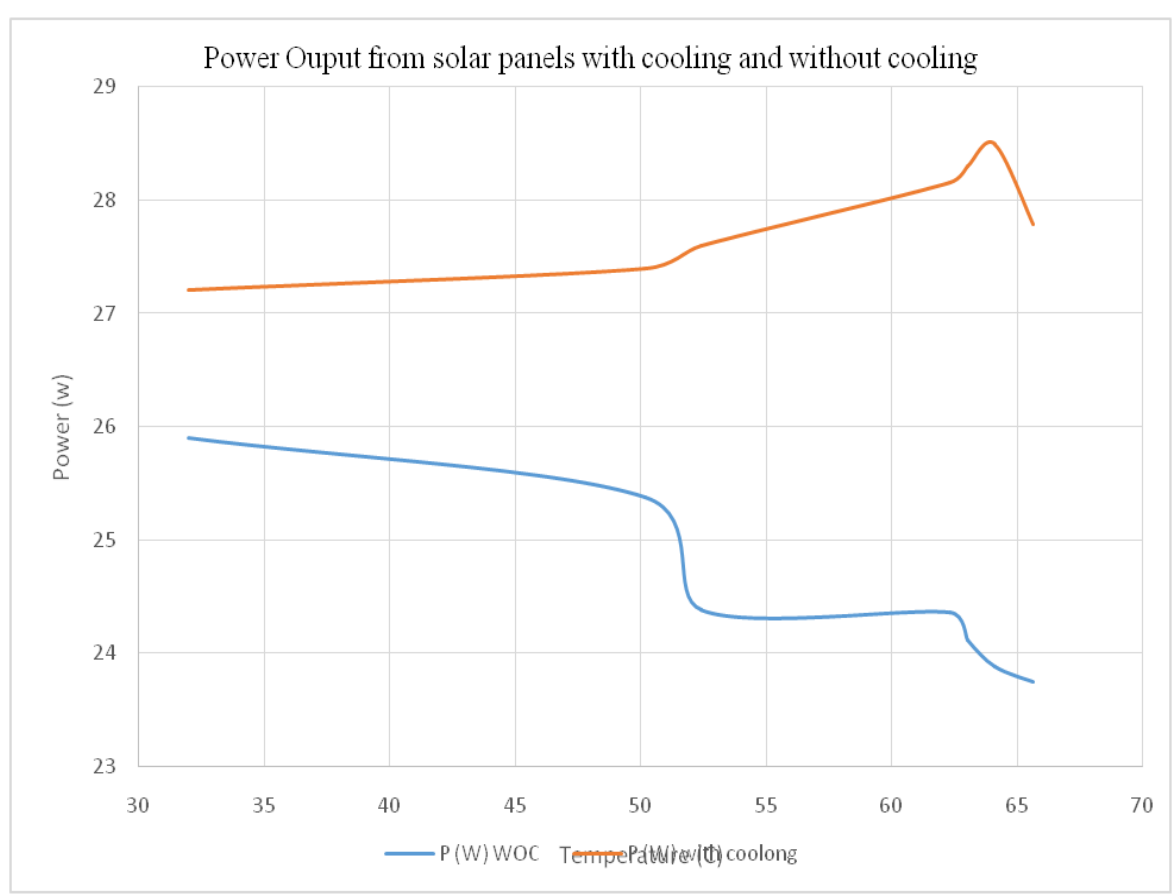

Figure 7: Effect of High Temperatures at the Surface of the Collector of Solar Energy Sector 


\section{Vibrations Effect}

The vibration of the tower affects the blade angle, the edge will pitch to the 90 or 2 degree setting. Since the sharp edge pitches rapidly, the relating enormous change in streamlined burdens bring about unusually huge vibration sizes for tower vibration. We can see that when the wind turbine closes down or fires up, Blade edge asymmetry is a typical sort of rotor blame and can prompt unsatisfactory weariness harm. At the point when this deficiency happens, the cutting edge plots for the turbine with three sharp edges become unique in relation to one another prompting asymmetry of streamlined stacking. In the event that wind turbine runs along these lines for expanded periods, the undesirable uneven burdens can make genuine harm the drive train and even the supporting structure[19, 20]. Figure 8 shows the impacts of vibration taken somewhere in the range of $10 \%$ and $75 \%$ as mastermind of impact with recurrence.

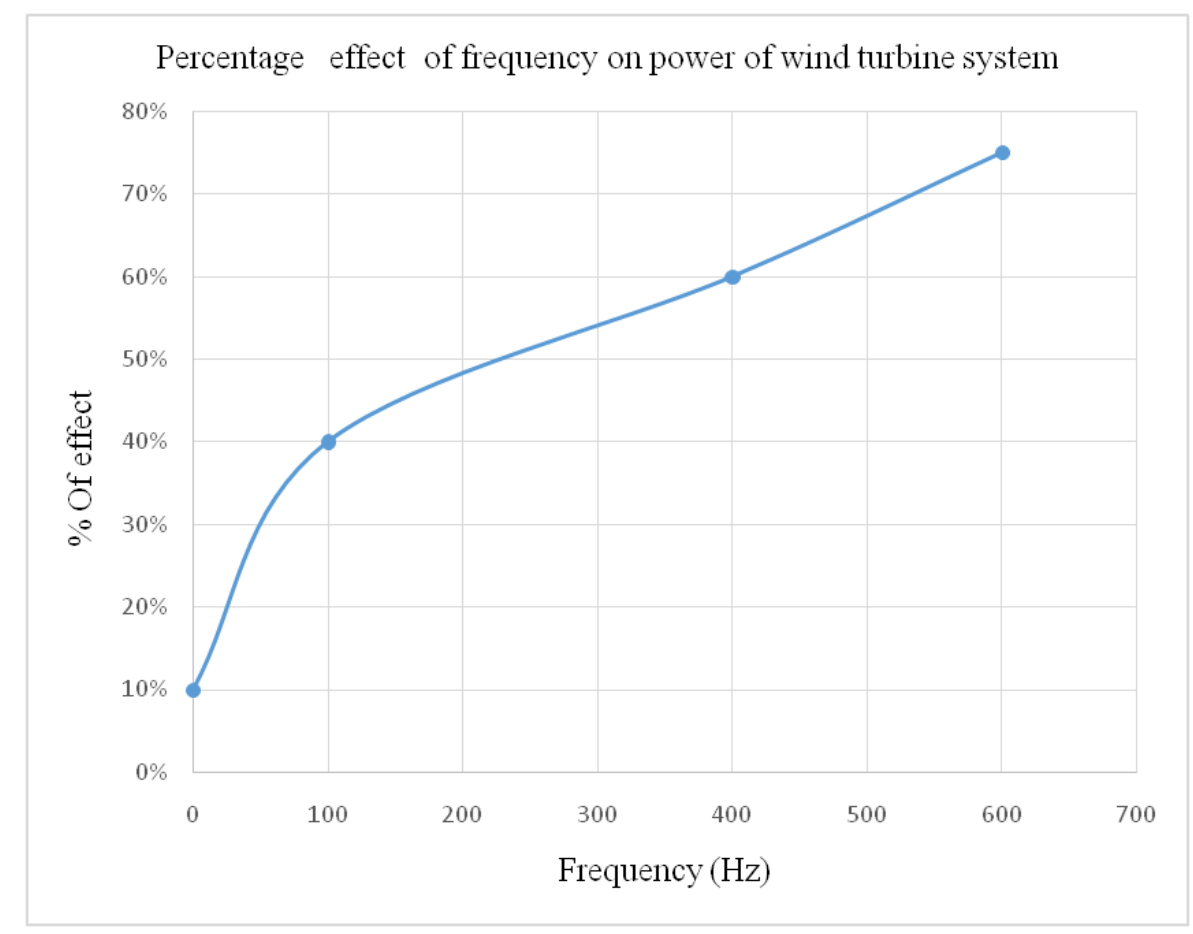

Figure 8: Impacts of Vibration on Final Efficiency of Wind Energy Sector

\section{CONCLUSIONS}

This paper discussed a suggested hybrid power plant that can use simultaneously solar panels and wind turbines to generate electrical energy through generators or invertors, the aim was to calculate the total efficiency of the hybrid power station and specifying the factors affects such systems and finally its performance. It is concluded that the combined systems effects on the resultant efficiency of the power plant it reaches to $70 \%$. There are many factors affects the final energy produced from hybrid energy systems (solar and wind). Two main factors are studied here: high temperatures, and vibrations both have a bad effect on the performance of the energy systems. As the temperature and vibrations increased the efficiency of the energies system (single or combined) is decreased.

\section{REFERENCES}

1. Dubey, S.; Tiwari, G.N. Thermal modeling of a combined system of photovoltaic thermal (PV/T) solar water heater. Sol. Energy 2008, 82, 602-612.

2. Tonui, J.K.; Tripanagnostopoulos, Y. Improved PV/T solar collectors with heat extraction by forced or naturalair circulation. 
Renew. Energy 2007, 32, 623-637.

3. Kluth, A. Using Water as a Coolant to Increase Solar Panel Efficiency; California State Science Fair: Los Angeles, CA, USA, 2008 .

4. Batoul, H. Technical Report: Flow Simulation Improves Photovoltaic Solar Panel Performance; Schueco International:Paris, France, 2008.

5. MuhammadAdil Khan, ByeonghunKo, EsebiAloisNyari, S. Eugene Park and Hee-Je Kim (2017). Performance Evaluation of Photovoltaic Solar Systemwith Different Cooling Methods and a Bi-ReflectorPV System (BRPVS): An Experimental Study andComparative Analysis. Energies 2017, 10, 826.

6. TDK(2010). solar energy: how to improve power efficiency level. http://www. uk.tdk-lambda.com.

7. Massimo Fiorentinia, Paul Cooper*a, ZhenunMaa and Duane A. Robinsona (2015) Hybrid model predictive control of a residential HVAC system withPVT energy generation and PCM thermal storageEnergy Procedia 83 ( 2015 ) 21 - 30

8. Fatima Zohra Zerhouni, M'hamedHouari Zerhouni, MansourZegrar, M. Tarik Benmessaoud, Amine Boudghene Stambouli, AbdelhamidMidoun (2010)Proposed Methods to Increase the Output Efficiency of a Photovoltaic (PV) SystemActa PolytechnicaHungarica Vol. 7, No. 2.

9. S. Adhikari and S. Bhattacharya (2011)Vibrations of wind-turbines consideringsoil-structure interaction. Wind and Structures, Vol. 14, No. 2 (2011) 85-11285

10. Mahmudur Rahman, ZhiChaoOng, Wen Tong Chong, Sabariah Julai and ShinYeeKhoo (2015).Performance enhancementofwindturbinesystemswithvibrationcontrol:AreviewRenewableandSustainableEnergyReviews51(2015)43-54.

11. Soufiane Karmouche And Anas Bentamy (2016). Tower Design and Analysis for a Small Wind Turbine. School of Science and Engineering-Alakhawin University.

12. K.V. Vidyanandan (2017). An Overview of Factors Affecting the Performance of Solar PV Systems. Energy Scan a house journal of Corporate Planning, NTPC Ltd., issue 27, pp. 2-8, Feb. 2017, New Delhi.

13. Ramadan J. Mustafa, Mohamed R. Gomaa, Mujahed Al-Dhaifallah and HegazyRezk. (2020). Environmental Impacts on the Performance of Solar Photovoltaic Systems Sustainability 2020, 12, 608; doi: 10.3390/su12020608.

14. Jordan Lofthouse, Randy T Simmons, andRyan M. Yonk [2015]. Reliability of Renewable Energy: Solar. Institute of political economy. UTAH state University

15. Nair Milind, Midhun Antony, Febin Francis, JithuFrancis, Joson Varghese, Sajith U K. (2017). Enhancing the Efficiency of Solar Panel Using Cooling Systems.Int. Journal of Engineering Research and Application. Vol. 7, Issue 3, (Part -4), pp.05-07.

16. Marisa Blackwood (2016).Maximum Efficiency of a Wind Turbine. Undergraduate Journal of Mathematical Modeling: One + Two. Volume 6 2016 Issue 2 | Article 2University of South Florida

17. Rahul Viswam and Dr. S. Sankar (2015) Efficiency Improvement of Wind Turbine Generator by Introducing Vortex. International Research Journal of Engineering and Technology (IRJET). Volume: 02 Issue: 03.

18. Birolini, Alessandro. (1997), Reliability of devices and systems, Springer-Verlag, Berlin, Heidelberg, New York.

19. PengGuoand David Infield (2012). Wind Turbine Tower Vibration Modeling and Monitoring by the Nonlinear State Estimation Technique (NSET). Energies 2012, 5, 5279-5293; doi:10.3390/en5125279 energies.

20. Hansen, Anca Daniela (2016)Introduction to wind power models for frequency control studies. DTU Wind Energy E, Vol.. 104

21. B. Jhansi Bai \& Ch. Rajesh Kumar, "Dynamic Model and Control of DFIG Wind Energy Systems Based on Power Transfer 
Matrix Using SVPWM", International Journal of Electrical and Electronics Engineering (IJEEE), Vol. 3, Issue 1, pp. 27-36

22. Monika Shekhar Gupta \& Y. P. SingH, “Climate Change and Public Awareness”, BEST: International Journal of Humanities, Arts, Medicine and Sciences (BEST: IJHAMS), Vol. 3, Issue 10, PP.113-124

23. S. Rajesh Rajan, "Power Quality Improvement in Grid Connected Wind Energy System Using UPQC", International Journal of Research in Engineering \& Technology (IJRET), Vol. 1, Issue 1, pp. 13-20

24. Jigar K. Parmar, Sunny K. Darji \& Gajendra R. Patel, "Fuzzy Based MPPT Controller of Wind Energy Conversion System using PMSG”, International Journal of Electrical and Electronics Engineering (IJEEE), Vol. 7, Issue3,pp. 17-30 

